\title{
Andrei Tyrsenko, ЭММАНРЭЛЬ ЖОЗЕФ СИЙЕС И ФРАНЦУЗСКАЯ ЛИБЕРАЛЬНАЯ МЫСЛЬ ЕГО ВРЕМЕНИ [Emmanuel Joseph Sieyès et la pensée libérale française de son époque]
}

\section{Varoujean Poghosyan}

\section{(2) OpenEdition}

Édition électronique

URL : https://journals.openedition.org/ahrf/11911

DOI : 10.4000/ahrf.11911

ISSN : 1952-403X

Éditeur :

Armand Colin, Société des études robespierristes

\section{Édition imprimée}

Date de publication : 1 décembre 2010

ISBN : 978-2-200-92634-2

ISSN : 0003-4436

\section{Référence électronique}

Varoujean Poghosyan, « Andrei Tyrsenko, Эмманрэль Жозеф Сийес и французская либеральная мысль его времени [Emmanuel Joseph Sieyès et la pensée libérale française de son époque] », Annales historiques de la Révolution française [En ligne], 362 I octobre-décembre 2010, mis en ligne le 25 mars 2011, consulté le 23 avril 2022. URL : http://journals.openedition.org/ahrf/11911 ; DOI : https:// doi.org/10.4000/ahrf.11911

Ce document a été généré automatiquement le 23 avril 2022.

Tous droits réservés 


\title{
Andrei Tyrsenko, эмМАнрэль ЖОЗЕФ СИЙЕС И ФРАНЦУЗСКАЯ
} ЛИБЕРАЛЬНАЯ МЫСЛЬ ЕГО ВРЕМЕНИ [Emmanuel Joseph Sieyès et la pensée libérale française de son époque]

\author{
Varoujean Poghosyan
}

\section{RÉFÉRENCE}

Andrei Tyrsenko, ЭММАНЬЭЛЬ ЖОЗЕФ СИЙЕС И ФРАНЦУЗСКАЯ ЛИБЕРАЛЬНАЯ МЫСЛЬ ЕГО ВРЕМЕНИ [Еmmanuel Joseph Sieyès et la pensée libérale française de son époque] Moscou, Éditions de l'Université de Moscou, 2005, 295 p.

1 Dans l'histoire de la Révolution française, l'activité des mouvements dits de droite a longtemps été délaissée par les historiens soviétiques. L'historiographie russe contemporaine essaie de corriger cette lacune; ainsi, Andrei Tyrsenko, maître de conférences à l'Université Lomonossov, élève d'Anatoli Ado, étudie depuis longtemps une histoire d'en haut, surtout centrée sur l'activité des Feuillants, à propos de laquelle il a publié un livre en 1999 (Les Feuillants. Aux origines du libéralisme français. En russe). Son nouvel ouvrage, consacré à l'évolution intellectuelle de Sieyès, est la première étude du genre dans l'historiographie soviétique/russe. En qualifiant son personnage de penseur allant des principes et de l'argumentation abstraite vers la pratique politique (p.3), il présente une interprétation profonde de l'évolution des idées de Sieyès de l'époque prérévolutionnaire à celle de Napoléon $\mathrm{I}^{\mathrm{er}}$. L'ouvrage repose sur le dépouillement d'une riche documentation, comprenant des œuvres imprimées, mais 
aussi de nombreux documents inédits tirés des papiers Sieyès conservés aux Archives nationales.

L'approche proposée est une interprétation des idées de Sieyès dans le contexte de la pensée libérale de son époque; l'auteur étudie ainsi l'évolution des idées philosophiques, sociales et politiques de Sieyès, ainsi que son activité politique lors de la Révolution, en relation avec la formation de ses conceptions constitutionnelles.

Andrei Tyrsenko analyse l'influence des idées des Lumières sur la formation de la pensée de Sieyès, qui a été non seulement, comme il l'affirme, l'interprète des philosophes, mais aussi un créateur d'idées sur la nature de l'État et la politique. L'auteur concentre d'abord son attention sur l'attitude de Sieyès vis-à-vis de l'absolutisme, que ce dernier proposait de remplacer par une monarchie constitutionnelle (p. 63-65), tout en rejetant le principe de la séparation des pouvoirs. À travers ses brochures (Essai sur les privilèges; Vues sur les moyens d'exécution dont les Représentants de la France pourront disposer en 1789 ; Qu'est-ce que le Tiers-état ?...), l'auteur étudie ses vues sur la nécessité de l'abolition des privilèges, du renversement de la monarchie absolue et de l'instauration d'un nouveau régime par l'adoption d'une Constitution dont le droit d'élaboration n'appartiendrait qu'à la nation. Andrei Tyrsenko conclut: "Les idées de Sieyès sur l'organisation constitutionnelle ont une grande portée théorique et sont à la base du constitutionalisme contemporain " (p.103). Il démontre ainsi qu'en 1788-1789, Sieyès a contribué à bâtir un nouveau système du pouvoir, celui de l'universalité souveraine nationale, qui s'exercerait par les représentants de la nation (p. 119).

4 Andrei Tyrsenko accorde une place majeure à l'activité de Sieyès pendant la Révolution, en discutant surtout sa participation à l'élaboration de la Déclaration des droits de l'homme et du citoyen, au triomphe de la souveraineté nationale et du régime représentatif, ainsi qu'à l'unification politique du territoire français. En confrontant la position de Sieyès avec celle des «partis » de l'Assemblée, Andrei Tyrsenko rapproche ses vues de celles d'Alexandre Lameth, particulièrement sur un point important: le transfert du pouvoir aux propriétaires, quels qu'aient été leurs anciens statuts juridiques (p. 157). Considérée par les Feuillants comme l'un des droits principaux, la propriété semblait permettre un rapprochement entre les anciens privilégiés et les couches possédantes du tiers état. Pour autant, en 1791-1792, Sieyès restait désireux de conserver les acquis de la Révolution, parce qu'il la considérait toujours comme une lutte entre le peuple et l'Ancien Régime (p. 176).

5 Sous la Convention, selon Andrei Tyrsenko, Sieyès se range parmi les membres du "Marais ». L'auteur analyse en détail sa participation aux travaux des comités de défense générale et d'Instruction publique, en soulignant que nombre de ses propositions n'ont pas été retenues. Néanmoins, le projet d'instruction publique adopté par la Convention thermidorienne se réfère à ses idées (p. 191-192). Intéressé par la politique extérieure et, selon Andrei Tyrsenko, partisan des "frontières naturelles ", Sieyès s'intéresse cependant avant tout aux questions constitutionnelles, particulièrement en l'an III. Aussi, l'auteur accorde une grande place à l'étude de l'époque thermidorienne, essentielle pour l'histoire ultérieure de ses vues politiques, parce que sa théorie constitutionnelle a été formée à cette époque. En se référant toujours aux droits de l'homme, Sieyès a mis à la base de sa vision de l'ordre public les notions de liberté, d'égalité (il ne s'agissait que de l'égalité des droits) et de propriété (p. 216). Andrei Tyrsenko a mis en évidence les différends entre Sieyès et les autres 
thermidoriens ; si ces derniers confondaient dans la Constitution les droits politiques des citoyens avec leurs droits civils, Sieyès, lui, accordait des droits civils à tous les Français (p. 219). Quant à l'organisation du pouvoir politique, l'auteur a très bien montré que Sieyès, n'acceptant pas toujours la théorie de la séparation des pouvoirs, ne confondait point le législatif avec l'exécutif. En même temps, il n'identifiait pas non plus ce dernier avec le gouvernement dont la fonction essentielle était, d'après lui, la préparation des propositions législatives (p. 225, 228). Or, ses propositions avaient été rejetées; d'après la Constitution adoptée en l'an III, les pouvoirs avaient été séparés. Comme l'auteur le note, "les nouvelles élites politiques n'ont pas été capables de préciser et de réaliser indépendamment la politique de la France républicaine dans le cadre de la Constitution de $1795 »$ (p. 235). Il le prouve en se référant aux coups d'État $\mathrm{du}$ Directoire. Dans ce cas, je partage son opinion. Néanmoins, citons à titre d'observation, qu'il a omis de discuter les explications de Jean-René Suratteau à propos de l'échec du gouvernement directorial. Était-ce la guerre qui a empêché les dirigeants de la République d'instaurer un gouvernement stable?

Andrei Tyrsenko poursuit en discutant les vues constitutionnelles de Sieyès en l'an VIII, quand ce dernier voulait encore instaurer un système représentatif au moyen de l'affirmation du pouvoir étatique, en citant dans ses ébauches, qu'il a redécouvertes dans ses archives, la priorité politique des élites révolutionnaires (p. 263). Il note avec raison que ses idées libérales ne correspondaient pas aux intentions du général Bonaparte. Le dernier chapitre du livre, également fondé sur des documents inédits, est consacré à l'évolution des idées philosophiques de Sieyès à l'époque napoléonienne, quand ses principes de l'éthique libérale ont été formulés.

7 Dans l'ensemble, Andrei Tyrsenko ne doute pas que Sieyès poursuivait toujours le but de remplacer au mieux l'ordre politique d'Ancien Régime ; mettant l'individu en avant, il avait rompu avec l'ancien ordre politique (p. 286). En outre, il souligne son rôle dans la formation des notions contemporaines comme "société politique», "peuple», « nation » que je ne puis ici présenter en détail. 